\title{
A dense GPS observation immediately after the 2004 mid-Niigata prefecture earthquake
}

\author{
Hiroaki Takahashi ${ }^{1}$, Takeshi Matsushima ${ }^{2}$, Teruyuki Kato ${ }^{3}$, Akira Takeuchi ${ }^{4}$, Teruhiro Yamaguchi ${ }^{1}$, Yuhki Kohno ${ }^{2}$, Takeshi Katagi $^{2}$, \\ Jun'ichi Fukuda ${ }^{3}$, Kazuya Hatamoto ${ }^{4}$, Ryousuke Doke ${ }^{4}$, Yuki Matsu'ura ${ }^{4}$, and Minoru Kasahara ${ }^{1}$ \\ ${ }^{1}$ Institute of Seismology and Volcanology, Graduate School of Science, Hokkaido University, Sapporo 060-0810, Japan \\ ${ }^{2}$ Institute of Seismology and Volcanology, Faculty of Sciences, Kyushu University, Shimabara 855-0843, Japan \\ ${ }^{3}$ Earthquake Research Institute, University of Tokyo, Tokyo 113-0032, Japan \\ ${ }^{4}$ Department of Earth Sciences, Toyama University, Toyama 930-8550, Japan \\ (Received February 15, 2005; Revised June 29, 2005; Accepted June 30, 2005)
}

\begin{abstract}
To investigate the postseismic crustal deformation associated with the 2004 mid-Niigata prefecture earthquake (M6.8), we newly started GPS observation to fill a gap of the nationwide continuous GPS network. Our GPS sites were mainly distributed in the focal region without permanent GPS site, and succeeded in obtaining the postseismic deformation. Coseismic displacements of two aftershocks were clearly detected because of immediate observation. Estimated fault parameters of the aftershock (M5.9) on November 8 occurring just beneath our GPS network indicated that geodetic data could be explained by either east- or west-dipping fault model inferred from detailed aftershock data. Moreover, clear postseismic deformation, which could be characterized by a logarithmic decay function, was observed. This signal probably suggests possible aseismic slip. Our results indicated that dense GPS observation could give important and interesting data to clarify the properties of shallow inland middle-size earthquakes.
\end{abstract}

Key words: The 2004 mid-Niigata prefecture earthquake, GPS, postseismic deformation, fault model, aseismic slip.

\section{Introduction}

The mid-Niigata prefecture earthquake (M6.8) occurred at shallow depth $(13 \mathrm{~km})$ on 23 October 2004 in Mid Niigata prefecture, central Japan. Focal mechanism estimated by the Japan Meteorological Agency (JMA) indicated pure reverse faulting with WNW-ESE compression axis (Fig. 1). Before occurrence of this earthquake, several researchers pointed out a seismic gap between the 1847 Zenkoji earthquake (M7.4) and the 1964 Niigata earthquake (M7.6) as shown in Fig. 1 (Ishikawa, 1995; Tsukuda, 1995; Ohtake, 2002). The 2004 earthquake partially filled this gap but not full.

It has been proposed that plate boundary between the Amurian and Okhotsk plates land at the southern edge of the 1964 earthquake fault (Nakamura, 1983; Kobayashi, 1983; Seno et al., 1996; Heki and Miyazaki, 2001). This hypothesis is consistent with geological and geophysical data in this region, e.g. active structure (Nakata and Imaizumi, 2002), active landslides, strain concentration revealed by nationwide GPS observation (Sagiya et al., 2000), and, of course, high seismicity. The epicenter of the 2004 earthquake was located in this active region.

In this report we introduce preliminary results of our new GPS observation and discuss several characteristics of postseismic crustal deformation.

Copy right (C) The Society of Geomagnetism and Earth, Planetary and Space Sciences (SGEPSS); The Seismological Society of Japan; The Volcanological Society of Japan; The Geodetic Society of Japan; The Japanese Society for Planetary Sciences; TERRAPUB.

\section{GPS Observation and Data Analysis}

The new GPS sites were established immediately after the occurrence of the mainshock by Hokkaido University, Kyushu University, the University of Tokyo and Toyama University. We first started the observation in October 24, the next day of the mainshock, at TODO site. Figure 1 shows the final distribution of our new GPS sites with the nationwide continuous GPS network (GEONET) sites operated by the Geographical Survey Institute. The GEONET sites were located only outside the aftershock area. In other words, average intersite distance of the GEONET (15-30 $\mathrm{km}$ ) is insufficient for $\mathrm{M}<7$ inland earthquakes because of an equivalent or smaller fault size. Therefore, our new sites distributed in the aftershock region would play a very important role for investigation of postseismic deformations. Antennas of the new GPS sites were fixed on the roof top of reinforced-concrete structures using buried stainless bolts, pillars, tripods and/or antenna attachments. We used dual frequency GPS receivers recording carrier phase at every $30 \mathrm{~s}$.

In this report we tried to analyze the data covering about one and half months after the mainshock occurrence. There was no snow covering on GPS antenna during this period. Our GPS data were processed with the GEONET data using the Bernese GPS Software Version 4.2 (Hugentobler et al., 2001) with International GPS Service for Geodynamics (IGS) precise ephemeris and International Earth Rotation Service parameters. The station coordinates and tropospheric parameters were estimated daily and every 3 

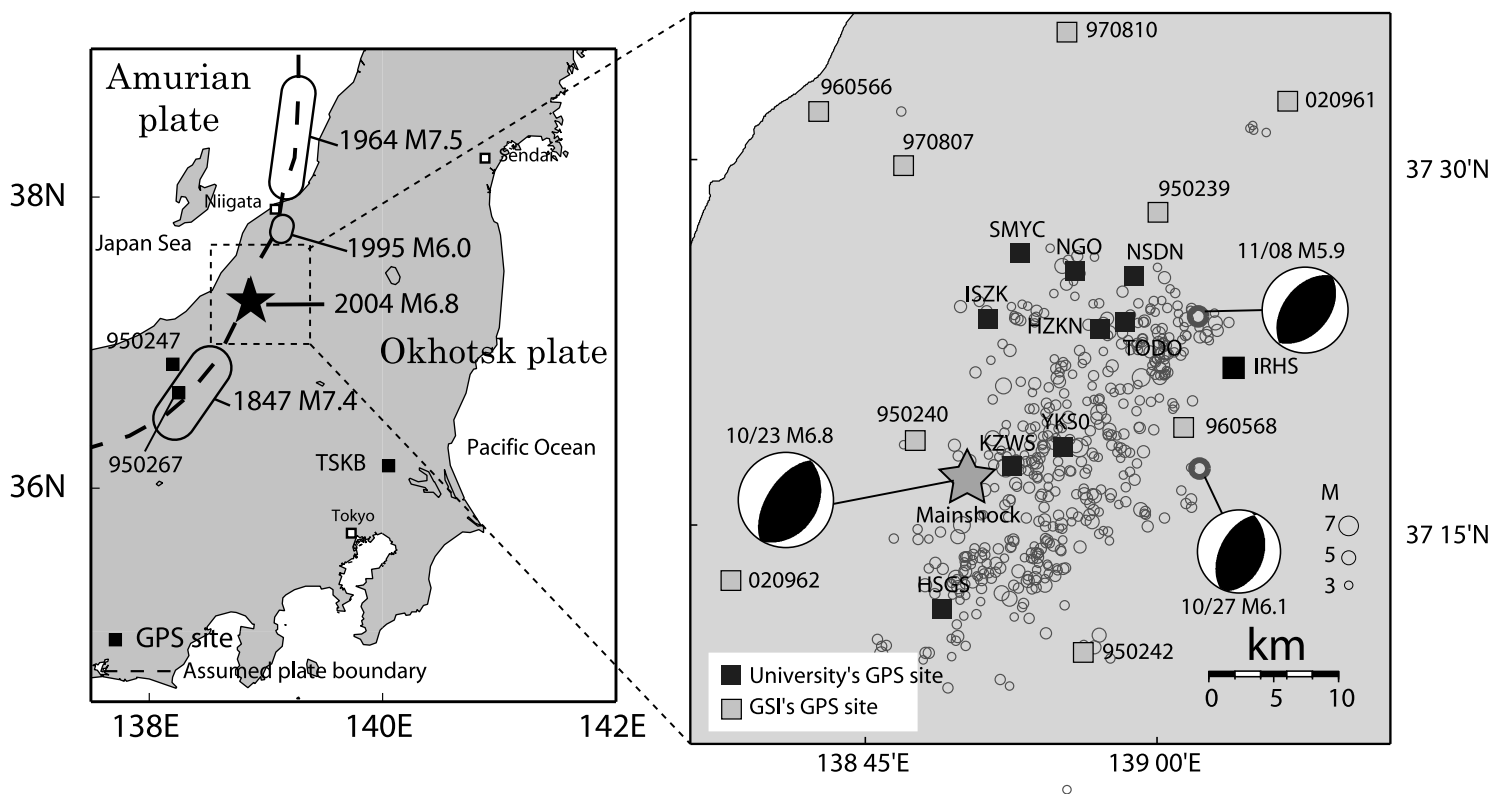

Fig. 1. Map showing the GPS sites. Focal regions of neighboring shallow large earthquakes along the plate boundary between the Amurian and Okhotsk plates (left) and $M \geq 3$ Aftershocks during a period from October 23 to December 15, 2004 (right), were also indicated. Mechanism solutions and epicenter distribution data were from the Japan Meteorological Agency.

\section{TODO}
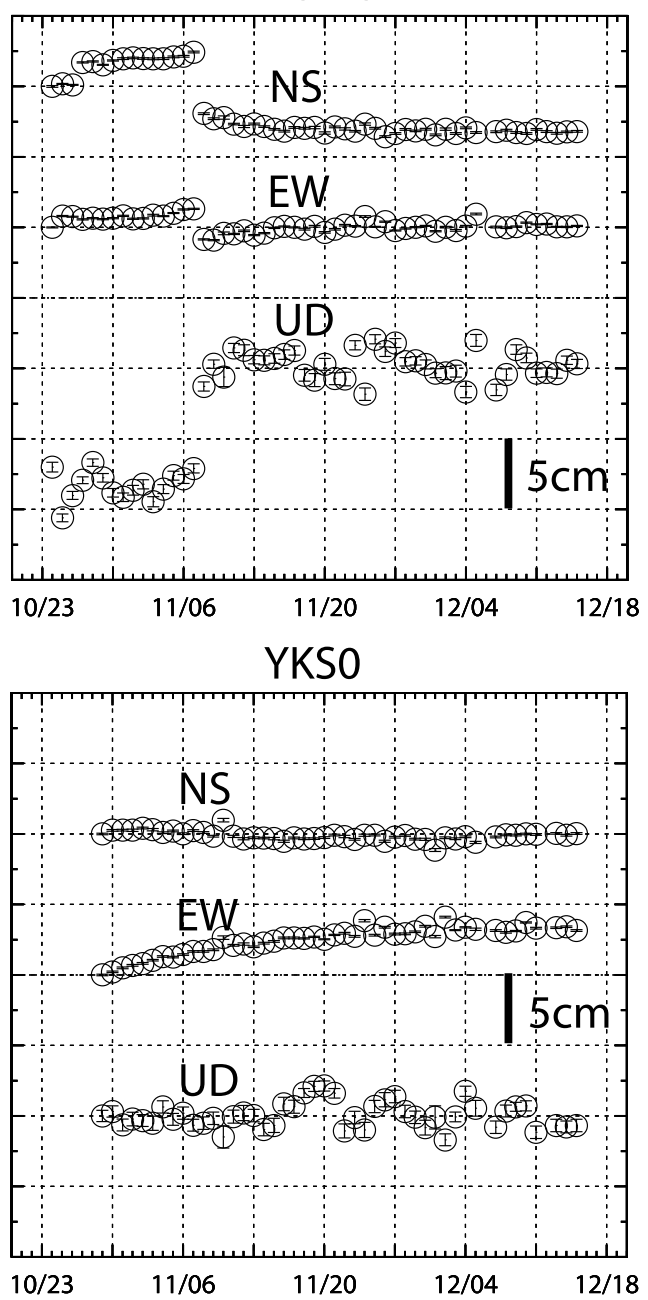

\section{NSDN}
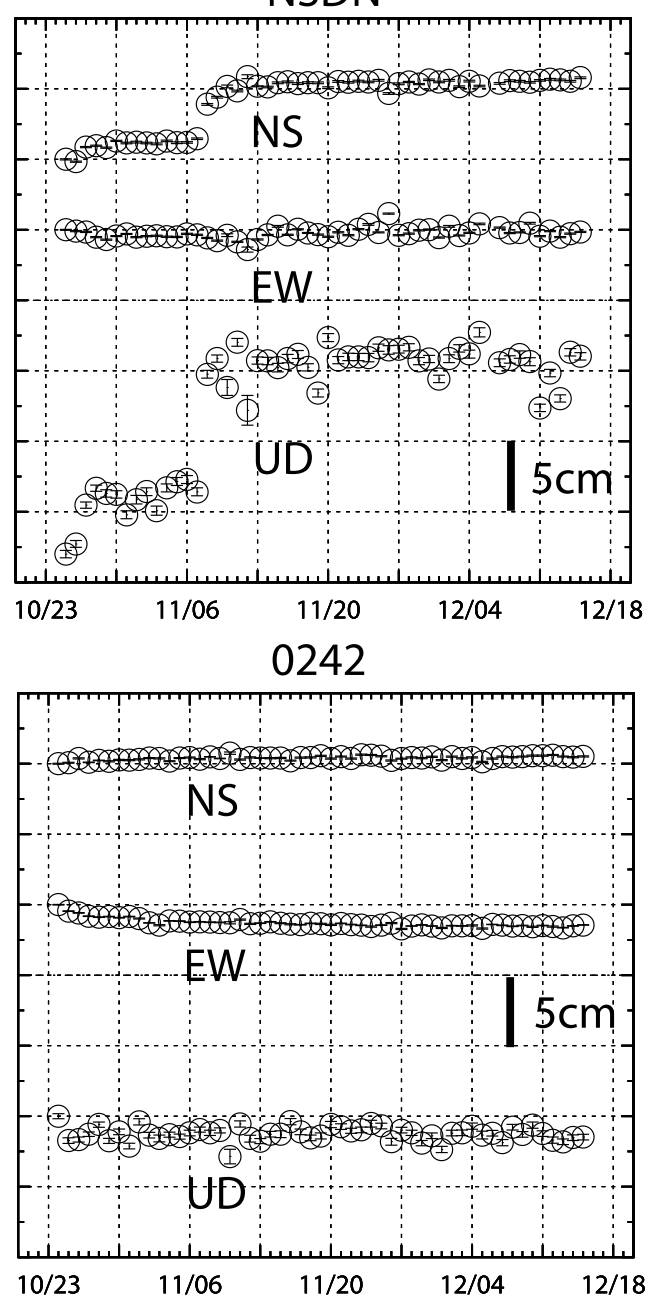

Fig. 2. Time series of coordinates and $2 \sigma$ formal errors at selected sites for the one and half months after the mainshock. 

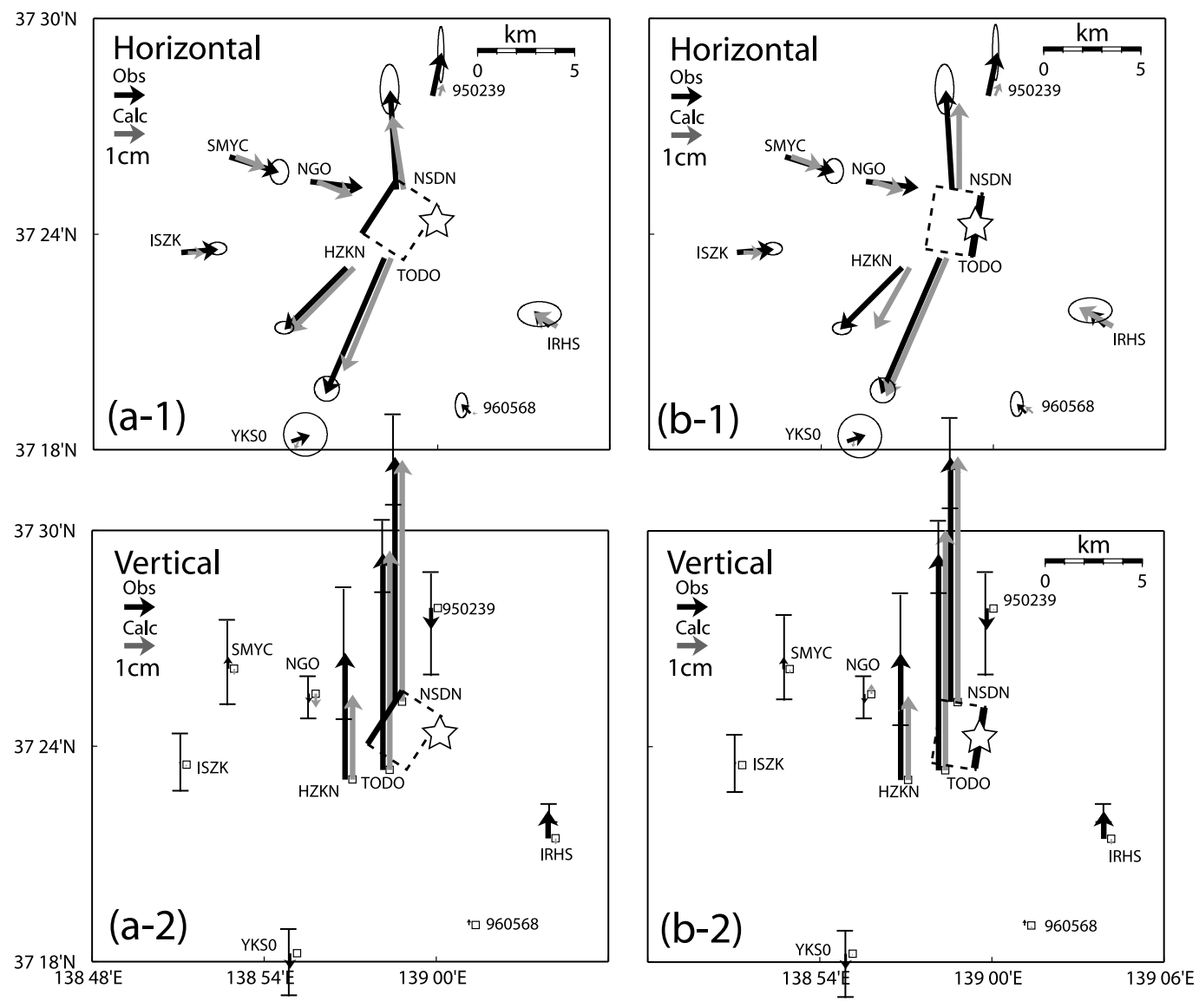

Fig. 3. Observed and calculated coseismic displacement field of an aftershock of November 8 (M5.9). Observed vectors and standard deviations were calculated from the average of three days coordinates before and after this earthquake. (a) East-dipping fault model and (b) west-dipping fault model were shown. Stars in (a) showed relocated epicenter of this earthquake by Kato et al. (2005), and in (b) by Shibutani et al. (2005).

Table 1. Estimated fault parameters of a November 8 aftershock (M5.9).

\begin{tabular}{|c|c|c|c|c|c|c|c|c|c|c|c|}
\hline & Latitude & Longitude & Depth (km) & Strike (deg) & Dip (deg) & Rake (deg) & $\mathrm{L}(\mathrm{km})$ & $\mathrm{W}(\mathrm{km})$ & $\mathrm{U}(\mathrm{cm})$ & $\mathrm{Mw}$ & $\mathrm{rms}$ \\
\hline East-dipping fault & 37.40 & 138.96 & 2 & 33 & 45 & 108 & 3.5 & 5.0 & 44 & 5.7 & 0.0130 \\
\hline West-dipping fault & 37.42 & 139.00 & 1 & 189 & 50 & 80 & 3.5 & 5.0 & 44 & 5.7 & 0.0133 \\
\hline
\end{tabular}

hours, respectively. Two sites of the GEONET, 950267 (Nagano City) and 950247 (Myoko-Kogen Town, southwestern Niigata Prefecture) were sufficient far from the focal region and were selected as reference sites. We confirmed high stability of both sites from seven year's daily site coordinates since 1996 published by the GSI ftp site (ftp://terras.gsi.go.jp). The initial coordinates of reference sites were collocated with the TSKB IGS station in the International Terrestrial Reference Frame 2000 (Altamimi et al., 2002).

\section{Result and Discussion}

3.1 Fault model estimation of an aftershock (M5.9) of November 8, 2004

Figure 2 shows daily site coordinate series at selected four sites. Clear offsets were recognized on October 27 and November 8 at TODO and NSDN. These step-like changes were induced by aftershocks of a M6.1 and a M5.9, respectively (Fig. 1). Particularly, many GPS sites recorded coseismic displacements of an aftershock on November 8 because this event occurred in the region where our GPS sites were densely distributed (Fig. 2).

We obtained the cosesicmic displacement data by comparing three days average coordinates of before and after this earthquake. The maximum coseismic signal of $4.9 \mathrm{~cm}$ in horizontal and $7.9 \mathrm{~cm}$ in vertical were observed at TODO and NSDN, respectively. However, little signals were detected at the GEONET sites. These results indicate dense GPS observation in advantageous for middle-size earthquakes.

Detailed aftershock distribution by Kato et al. (2005) indicated east-dipping alignment, but Shibutani et al. (2005)'s aftershock data showed west-dipping tendency. Therefore, we tried to look for best-fitting fault parameters for either east- or west-dipping fault plane by grid search procedure. Theoretical crustal deformation was calculated using horizontal and vertical components data with same weighting by using a simple, rectangular fault model in an elastic half space (Okada, 1985). Estimated fault parameters for both models were shown in Fig. 3 and Table 1. RMS residuals estimated by both fault models showed approximately the same values (Table 1). This indicated that geodetic 


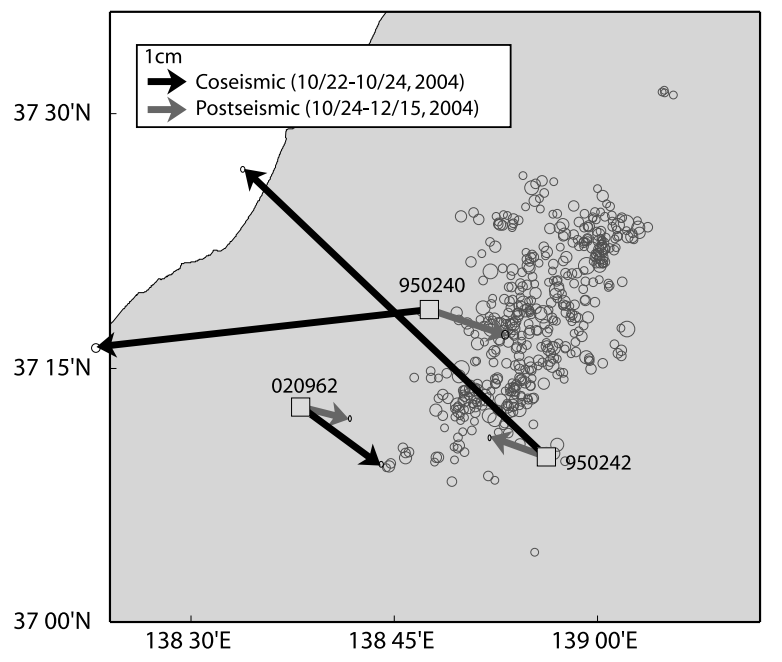

Fig. 4. Comparison of coseismic and postseismic horizontal displacement vectors from daily coordinate difference with $2 \sigma$ formal errors. Postseismic vector at 950240 indicates opposite direction of coseismic one.

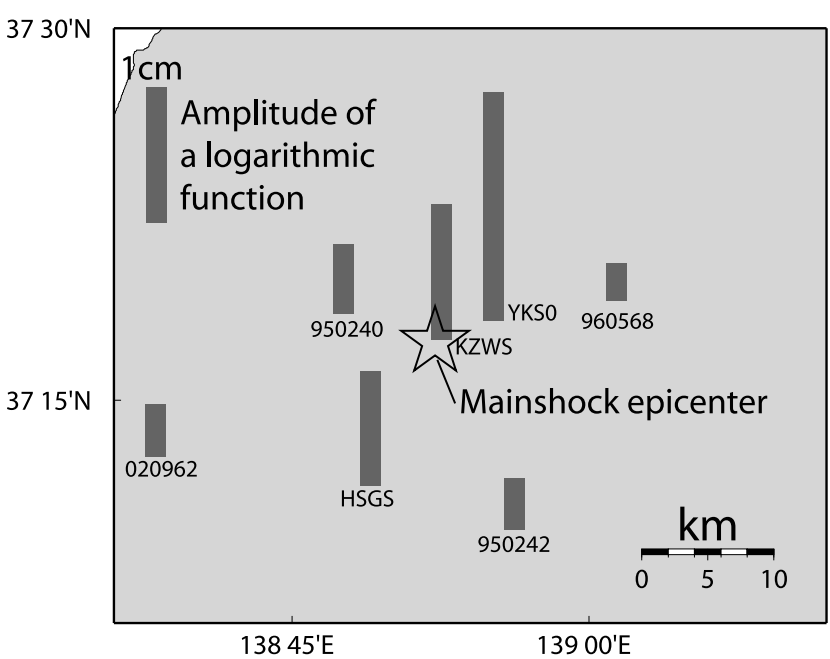

Fig. 6. Amplitude distribution of a logarithmic decay functions under a fixed time constant ( 0.21 days). Only sites with little coseismic deformation of October 27 and November 8 earthquakes were shown.
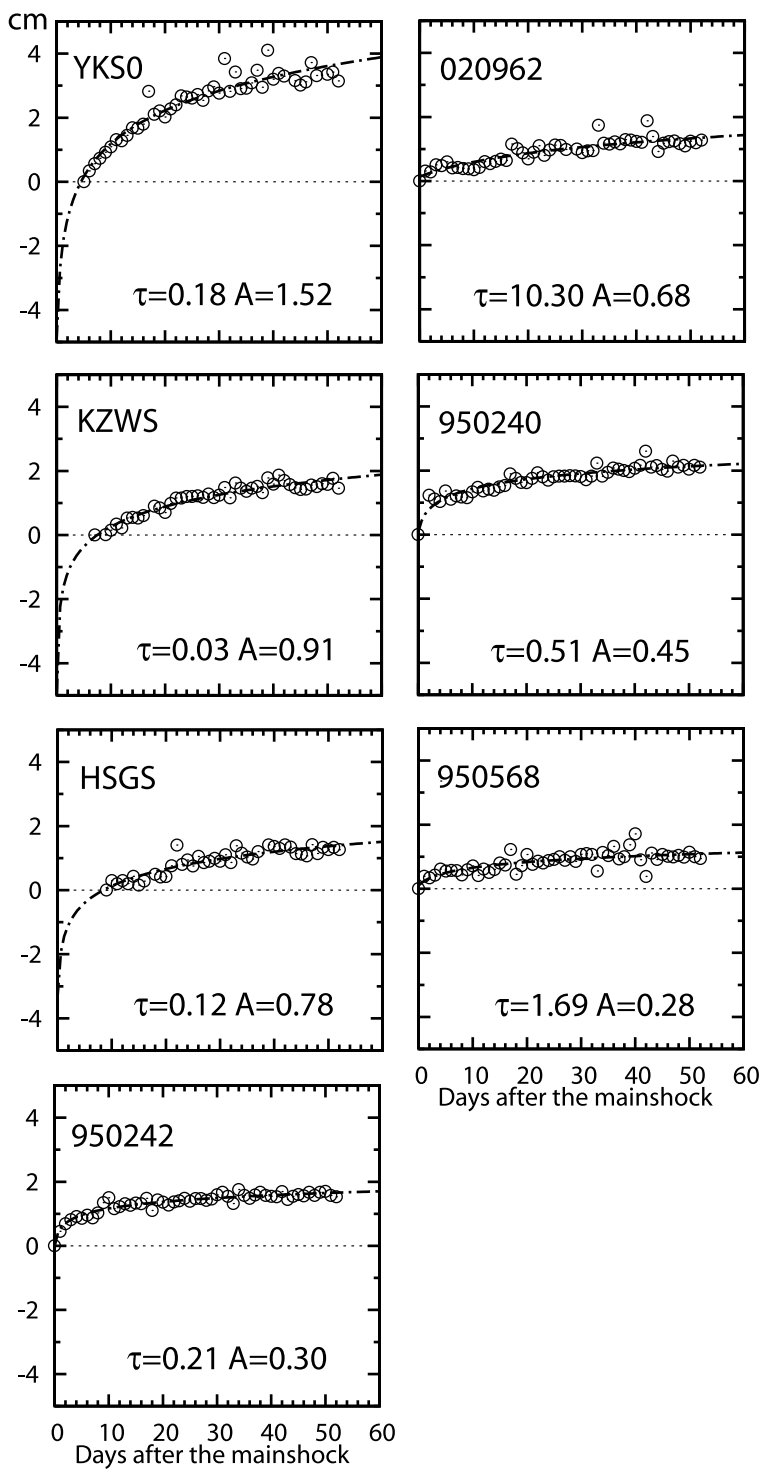

Fig. 5. Time series of length of the daily horizontal displacement projected onto the direction along which the horizontal signals are the largest. Time constant in days $(\tau)$ and amplitude in $\mathrm{cm}(A)$ were also shown. data could be explained by either east- or west-dipping fault plane model.

\subsection{Postseismic signals}

Small but detectable postseismic deformations were observed at YKS0, KZWS, HSGS, 950242, 020962, 950240 and 950568 in horizontal component. We observed the maximum postseimic signal of $3.2 \mathrm{~cm}$ in horizontal component at YKS0, which was approximately twice as large as observed at the GEONET sites. Although it was difficult to extract the postseismic signal from the daily coordinates at sites where coseismic displacements of aftershocks were observed, for example, NSDN, TODO, HZKN, it was possible that postseimic components of these sites were smaller than a centimeter. Sites with relative large amplitude, that are YKS0 and KZWS (Fig. 2), were situated near the mainshock epicenter where the maximum coseismic slip was estimated (Yamanaka, 2004; Yagi, 2004; Honda et al., 2005). A postseismic displacement of $2.1 \mathrm{~cm}$ at 950240 corresponds to the $25 \%$ of coseismic one (Fig. 4). Though coseismic displacement at this site was to the westward, postseismic had eastward direction (Fig. 4). This fact may reflect complex faulting in mainshock and aftershock sequence as indicated by seismological data (e.g. Shibutani et al., 2005; Kato et al., 2005).

The postseismic deformation rate seems to change with time. We tried to estimate a time-dependent relaxation function. To extract the characteristics of this deformation, we examined the logarithmic decaying model, which is commonly used to model afterslip (e.g. Scholz, 1990). The logarithmic decay model is expressed as

$$
R(A, \tau)=A \ln (1+t / \tau)
$$

where $t$ is the time elapsed after the mainshock, $A$ is the amplitude of the function, and $\tau$ is the time constant. Unknown parameters, $A$ and $\tau$, were estimated from the length of the daily horizontal displacement projected onto the direction along which the horizontal signals are the largest for each GPS site. Calculated $\tau$ values ranged from 0.03 to 1.69 days except for those at 020962 (Fig. 5). We suppose this 
rapid decay is one of typical characteristics of afterslip of large earthquake (Scholz, 1990).

If the postseismic crustal deformation is the manifestation of the same afterslip at depth, the time constant should be same for all sites. Therefore, we estimated amplitudes of this decay function by fixing $\tau$ as that at 950242. Sites with little coseismic deformation due to the October 27 and November 8 aftershocks were selected for analysis, and the results were shown in Fig. 6. Relative large postseismic amplitudes were estimated at the sites in the southern part of the focal region. Ozawa et al. (2005) suggested a possible aseismic slip in the shallower part of the Western Muikamachi Basin fault by InSAR data. Observed postseismic signals by the present study may also indicate possible aseismic slips.

\section{Conclusion}

We successfully established new GPS sites in the focal region of the 2004 mid-Niigata prefecture earthquake (M6.8) immediately after the mainshock. Analysis of data obtained for a period of one and half months after the mainshock clearly recorded the coseismic displacements by the M5.9 aftershock and horizontal postseismic deformation. Fault model estimation of the M5.9 event suggested that geodetic data could be explained by either east- or westdipping fault model inferred from detailed aftershock studies (Kato et al., 2005; Shibutani et al., 2005). Coordinate time series were modeled with a logarithmic function, which agree with the characteristics of afterslip of a large earthquake. Postseismic signals were relatively larger at sites in the southern part of the focal region, which implied possible aseismic slip. Dense GPS observation could give important and interesting data to clarify the properties of shallow inland middle-size earthquakes.

Acknowledgments. We are grateful to the staff of schools, local governments and farmers cooperative who permitted us to install GPS receivers. Makiko Iwakuni at University of Tokyo, Sayaka Uchiumi and Yasuko Shimizu at Tokai University help us to collect observation data. We are thankful to Prof. N. Hirata and anonymous reviewer for their constructive comments, and Prof. Y. Nishida for proofreading. We obtained GPS RINEX data from Geographical Survey Institute of Japan, which is appreciated. Focal mechanism data in Fig. 1 were from JMA's home page (http://www.jma.go.jp). Hypocenter data in Fig. 1 were quickly determined by JMA in cooperation with the Ministry of Education, Culture, Sports, Science and Technology (MEXT) to analyze seismic wave data provided by cooperative organizations, that is Hokkaido Univ., Hirosaki Univ., Tohoku Univ., University of Tokyo, Nagoya Univ., Kyoto Univ., Kochi Univ., Kyushu Univ., Kagoshima Univ., National Research Institute for Earth Science and Disaster Prevention, National Institute of Advanced Industrial Science and Technology, the Tokyo Metropolitan Government, Shizuoka Prefecture, Hot Springs Research Institute of Kanagawa Prefecture, Yokohama City, Geographical Survey Institute and Japan Marine Science and Technology Center. This research is supported by the New Program for Earthquake Predic- tion Research and Observation, and Grand-in-Aid for Scientific Research (representative; N. Hirata) of MEXT of Japan Government. Figures were partially drawn using GMT software (Wessel and Smith, 1995).

\section{References}

Altamimi, Z., P. Sillard, and C. Boucher, ITRF2000: A new release of the International Terrestrial Reference Frame for earth science applications, J. Geophys. Res., 107, 2214, doi:10.1029/2001JB000561, 2002.

Heki, K. and S. Miyazaki, Plate convergence and long-term crustal deformation in central Japan, Geophys. Res. Lett, 28, 2313-2316, 2001.

Honda, R., S. Aoi, N. Morikawa, H. Sekiguchi, T. Kunugi, and H. Fujiwara, Ground motion and rupture process of the 2004 Mid Niigata Prefecture earthquake obtained from strong motion data of K-NET and KiK-net, Earth Planets Space, 57, 527-532, 2005.

Hugentobler, U., S. Schaer, and P. Fridez, Bernese GPS Software Version 4.2, University of Bern, 515 pp, 2001.

Ishikawa, Y., Northern Niigata Earthquake and seismic gap, Earth Monthly, 17,784-788, 1995.

Kato, A., S. Sakai, N. Hirata, E. Kurashimo, S. Nagai, T. Iidaka, T. Igarashi, Y. Yamanaka, S. Murotani, T. Kawamura, T. Iwasaki, and T. Kanazawa, Short-term spatiotemporal variations in the aftershock sequence of the 2004 mid-Niigata prefecture earthquake, Earth Planets Space, 57, 551-556, 2005.

Kobayashi, Y., Initiation of subduction of a plate, Earth Month., 5, 510 514, 1983 (in Japanese).

Nakamura, K., Possibility of a nascent plate boundary at the eastern margin of the Japan Sea, Bull. Earthquake Res. Inst., Univ. Tokyo, 58, 711-722, 1983 (in Japanese).

Nakata, T. and T. Imaizumi (ed.), Digital Active Fault Map of Japan, University of Tokyo Press, 2002.

Ohtake, M., Earthquake occurrence potential in eastern margin of the Japan Sea, in Active Faults and Seismi-tectonics of the Eastern Margin of the Japan Sea, edited by M. Ohtake, A. Taira, and Y. Ohta, University of Tokyo Press, 2002.

Okada, Y., Surface deformation due to shear and tensile faults in a half space, Bull. Seis. Soc. Am., 75, 1135-1154, 1985.

Ozawa, T., S. Nishimura, Y. Wada, and H. Ohkura, Coseismic deformation of the Mid Niigata prefecture Earthquake in 2004 detected by RADARSAT/InSAR, Earth Planets Space, 57, 423-428, 2005.

Sagiya, T., S. Miyazaki, and T. Tada, Continuous GPS Array and Presentday Crustal Deformation of Japan, PAGEOPH, 157, 2303-2322, 2000.

Scholz, C. H., The Mechanics of Earthquakes and Faulting, Cambridge University Press, 1990.

Seno, T., T. Sakurai, and S. Stein, Can the Okhotsk plate be discriminated from the North American plate?, J. Geophys. Res., 101, 11305-11315, 1996.

Shibutani, T., Y. Iio, S. Matsumoto, H. Katao, T. Matsushima, S. Ohmi, F. Takeuchi, K. Uehira, K. Nishigami, B. Enescu, I. Hirose, Y. Kano, Y. Kohno, M. Korenaga, Y. Mamada, M. Miyazawa, K. Tatsumi, T. Ueno, H. Wada, and Y. Yukutake, Aftershock distribution of the 2004 Mid Niigata Prefecture Earthquake derived from a combined analysis of temporary online observations and permanent observations, Earth Planets Space, 57, 545-549, 2005.

Tsukuda, T., Possibility of large earthquake occurrence in Niigata plain, Earth Monthly, 17, 789-796, 1995.

Wessel, P. and W. H. F. Smith, New version of the Generic Mapping Tools released, EOS Trans. AGU, 76, 329, 1995.

Yagi, Y., http://iisee.kenken.go.jp/staff/yagi/eq/20041023/, 2004.

Yamanaka, Y., EIC seismological note, no. 154, http://www.eri.u-tokyo.ac. jp/sanchu/Seismo_Note/, 2004.

H. Takahashi (e-mail: hiroaki@eos.hokudai.ac.jp), T. Matsushima, T. Kato, A. Takeuchi, T. Yamaguchi, Y. Kohno, T. Katagi, J. Fukuda, K. Hatamoto, R. Doke, Y. Matsu'ura, and M. Kasahara 